\title{
Technocratic Management Versus Ethical Leadership Redefining Responsible Professionalism in the Agri-Food Sector in the Anthropocene
}

\author{
Vincent Blok ${ }^{1}$
}

Accepted: 6 October 2018 / Published online: 11 October 2018

(c) The Author(s) 2018

\begin{abstract}
In this contribution, we argue that three related developments provide economic, environmental and social challenges and opportunities for a new responsible professionalism in the food chain: (1) the Anthropocene; (2) the bio-based economy; (3) Precision Livestock Farming. These three interrelated developments indicate a transition in the way we understand the role and function of the food chain on the micro-, the meso- and the macro-level. This transition can be understood in two fundamental different ways, namely either as an extension of technocratic management beyond the micro level to the meso- and macro-level of the food chain, or as a transition to a new responsible professionalism. We argue that the technocratic approach is not able to address the socio-ethical issues that come along with these three development, and argue for a new responsible professionalism in the agri-food chain in the Anthropocene based on normative and action competence.
\end{abstract}

Keywords Food chain - Anthropocene $\cdot$ Biobased economy $\cdot$ Precision livestock farming $\cdot$ Responsible professionalism

\section{Introduction}

In this contribution, we argue that three related developments-the new geological epoch which is called the Anthropocene, the transition to the bio-based economy (BBE), and the introduction of precision lifestock farming (PLF) - provide economic, social and environmental challenges for the agri-food sector, but also opportunities for a new conceptualization of responsible professionalism. With the emergence of the Anthropocene, we are at the crossroads of two main human responses to these challenges and opportunities that we face. We can choose either for a new

Vincent Blok

vincent.blok@wur.nl

1 Social Sciences Group, Wageningen University, Hollandseweg 1ne, $6707 \mathrm{KN}$ Wageningen,

The Netherlands 
type of responsible professionalism based on technocratic management and control, or based on ethical leadership.

We will first argue why especially these three developments show the limitations of the technocratic approach and call for a new type of responsible professionalism in the agri-food sector. A new type of professionalism is argued for, because we will secondly argue that current forms of ethical leadership unwittingly subscribe to the idea of planetary management and control. In contrast, we will argue for a new responsible professionalism based on normative and action competence.

\section{Three Contemporary Developments in the Agri-Food Sector}

We can identify three contemporary developments in the agri-food sector, that provide economic, social and environmental challenges for the agri-food sector, but also opportunities for a new conceptualization of responsible professionalism:

1. The changed conditions under which the contemporary food chain operates can be conceptualized in terms of the Anthropocene; the Anthropocene is a new geological epoch, in which the human has become the most influential 'terraforming' factor on earth (Blok 2017). Climate change is one of the main characteristics of the Anthropocene. We have only one Earth available on which we all depend. On the one hand, it shows the dependency of the food chain on Earth's carrying capacity to feed the world. On the other hand, therefore, this calls for the transition to a more sustainable food chain that remains within the carrying capacity of planet Earth. A shift in the food chain is required from a primary focus on market value and market growth, to a focus on earth-oriented value, that provides huge challenges and opportunities for a new responsible professionalism in agri-food practices (cf. Bovenkerk and Keulartz 2016).

2. One way to operationalize this shift is the transition to the bio-based economy (BBE). The BBE mimics natural cycles and can be defined as a "production paradigm that rely on biological processes and, as with natural ecosystems, use natural inputs, expend minimum amounts of energy and do not produce waste as all materials discarded by one process are inputs for another process and are reused in the ecosystem" (European Commission 2012). Because the transition to the BBE provides a paradigm in which earth-oriented values become central in and form the basis of economic considerations, while it at the same time raises ethical issues of inter- and intra-generational equity (Murray et al. 2017), the BBE provides huge challenges and opportunities for a new responsible professionalism in the food chain.

3. One way to operationalise the BBE in practice is the introduction of Precision Life Stock farming (PLF). PLF can be defined as "the management of livestock production using the principles and technology of process engineering... PLF treats livestock production as a set of interlinked processes, which act together in a complex network" (Wathes 2009). By the integration of smart technology and the internet of things-in which computers, sensoring devices, GPS systems 
but also robots and even animals communicate with one another and function autonomously in an integrated farm management system-farmers can reduce farm inputs (fertilizers and pesticides) and increase yields, while reducing emissions to the environment (Bos and Munnichs 2016). In PLF, the internet of things is extended to farm animals (Blok and Gremmen 2018). Because PLF provides concrete strategies to manage and control sustainable production in the food chain, while it at the same time raises ethical issues associated with the increased corporatization and industrialization of the agricultural sector, PLF provides both opportunities and challenges for a new responsible professionalism in the food chain.

These three interrelated developments indicate a transition in the way we understand the role and function of the food chain on the micro-, the meso- and the macro-level.

\section{Two Main Human Responses to These Challenges and Opportunities in the Anthropocene}

This transition can be understood in two fundamental different ways, namely either as an extension of technocratic management and control beyond the micro level to the meso- and macro-level of the food chain, or as a transition to a new responsible professionalism. Why?

The notion 'Anthropocene' does not only describe the current geological epoch in which humanity determines the face of the Earth, but makes us sensitive for the idea that we have to take responsiblity for Earth's life-support systems on Earth (Kolbert 2011). This responsibility is often understood in terms of planetary engineering and management of the Earth: "... the condition of the patient is serious, possibly terminal. [We] are now in a critical and exceptional state. This both generates and draws upon an attraction to global-scale technological 'solutions' and earth management, under the guidance of the scientists-engineers best placed to understand, interpret and help shape the necessary interventions. [with this, we either intend to] bring us back from the brink, or at taking us to a new and better-managed future Earth" (Baskin 2015, 22). The earth becomes a spaceship that has to be steered and managed by humanity in order safeguard its future (Blok 2017).

In the context of the $\mathrm{BBE}$, we can concretely think of mitigation strategies to improve resource efficiency of agri-food products via biotechnology, feed ingredient optimisation, waste reduction and better control of reproduction processes (European Commission 2012). In the context of PLF, we can think of the introduction of integrated farm management systems that enable further intensification of livestock farming and the emergence of megastalls in general, and the monitoring and control of animal growth, milk or egg production and greenhouse gas emissions in particular (Blok and Gremmen 2018; Bos and Gremmen 2013; Harfeld 2010).

We can frame these strategies in the BBE and PLF as technocratic management and control interventions. Technocracy is the idea of management and control of the food chain by technical experts. The farmer is no longer primarily the producer of 
food products, but a data processor and data manager that controls automated farm management systems. By exchanging information about oestrus detection, health, feed intake, waste material etc., food chain actors are enabled to optimize coordination and efficiency throughout the supply chain (Blok and Gremmen 2018). The advantage of the technocratic approach of the BBE and PLF is the eco-efficiency of agri-food production and consumption it can achieve, while contributing to economic returns as well.

At the same time, the technological fixes of the technocratic approach obscures the complexity of the ecological problems we face in the Anthropocene and the socio-technological systems in which they appear. A technological fix can be defined as follows: "Recasting all complex social situations either as neatly defined problems with definite, computable solutions or as transparent and self-evident processes that can be easily optimized- if only the right algorithms are in place" (Morosov 2013). It neglects the 'wickedness' of problems like climate change in the Anthropocene, the normative dimension of BBE and the conflicting values involved in PLF.

\section{Why Technocratic Management and Control is Insufficient in the Anthropocene}

Climate change can be considered a wicked problem, i.e., a problem that is ill structured, difficult to pin down and unsolvable in a way. If we consider the famous definition of sustainable development from the Brundlandt report-Our common future-(World Commission on Environment and Development 1987) it seems to be quite simple: the use of resources today should not constrain the use of (non-renewable) resources in the future. But if we take the carrying capacity of the earth as point of departure and, with this, the fact that every resource will eventually be exhausted if we continue our current patterns of production and consumption, it becomes clear that climate change is a sustainability related eco-system failure that is difficult to pin down and highly complex, just like its solution (Peterson 2009; Blok 2018). In fact, it is not possible to satisfy the needs of the current generation without changing the conditions for future generations. Because climate change is a wicked problem that has no closed form and concerns the eco-systems of planet Earth in which cause and effect are uncertain or unknown, no simple or partial solutions exists for such a problem. First of all, there are no definite solutions if we do not have a definite problem description. Secondly, all solutions remain finite and provisional compared to the complexity and depth of the sustainability problem itself. We therefore cannot reduce sustainability to a finite set of particular 'problems', nor say that these 'problems' can ultimately be solved by partial solutions. This is to say, sustainability can never be fully achieved (Blok et al. 2016). Because of its focus on partial problems and efficient solutions, it is highly questionable whether technocratic management and control is sufficient to address wicked problems like climate change in the Anthropocene.

The same holds for the transition towards the bio-based economy. While current developments in the $\mathrm{BBE}$ are promising, most strategies are focussing on the technical issues to improve eco-efficiency in the food chain, whilst the normative 
dimension of the transition to the BBE are not taken into account. Sustainable development is a normative notion because it doesn't describe the world as it is, but as it should be. This means that the normative and socio-economic barriers to the transition towards the BBE should be taken into account. The transition to the $\mathrm{BBE}$ raises for instance ethical issues concerning inter-and intra-generational equity. Current investments in green technology and solar panels make use of scarce metals for instance. The demand for biofuel for instance has resulted in the replacement of tropical forests by soy fields (Farigone et al. 2008), putting pressure on food production in poor countries (cf. Murray et al. 2017). Because costs and benefits or risks and rewards are difficult to calculate for future generations, if not impossible, it is questionable whether technocratic management and control is sufficient to address these type of questions in current research and policy making processes (Schlaile et al. 2017), or requires a fundamental reflection on the relation between the biosphere and the economic sphere in the BBE (Zwier et al. 2015).

A same pattern can be articulated based on the emergence of precision lifestock farming. While current developments in PLF are promising, it also raise ethical issues associated with the further intensification and industrialisation of livestock farming, like the emergence of megastalls with various socio-ethical consequences (Bos and Gremmen 2013). More in general, it may result in the alienation between animals, farmers and citizens because of the robotisation and digitalization of farm management systems (Bos and Munnichs 2016; Blok and Gremmen 2018). Because the solution of these social-ethical issues cannot be calculated by experts but require public engagement, it is questionable whether technocratic management and control is sufficient to address the socio-ethical issues that make society reluctant to accept PLF.

Because the three interrelated developments-Anthropocene, biobased economy and precision livestock farming - indicate a transition in the way we understand the role and function of the food chain on the micro-, the meso- and the macro-level, but the technocratic approach is not able to address the socio-ethical issues that come along with it, we argue for a new responsible professionalism in the food chain.

\section{Do Current Conceptualizations of Responsible Professionalism Move Beyond Technocratic Management and Control of Planet Earth?}

It is relatively easy to feel moral superior by criticizing technocratic management and control and by calling for ethical leadership in the Anthropocene. We can argue however that not only technocratic management and control subscribes to planetary engineering and management of the humanized Earth in the Anthropocene. We normally distinguish between an attitude towards the natural environment of planet Earth that is characterized by the exploitation of nature as a means to human ends, and an attitude that is characterized by the respectful exploration of nature as an end in itself. An example of the first attitude can be found in the strategy to introduce radical new technologies and control systems to save planet Earth, like anthropogenic emissions of aerosol particles into the atmosphere to counter greenhouse gas effects, or the sequestration of $\mathrm{CO} 2$ in underground reservoirs (cf. Steffen et al. 
2007). An example of the second attitude can be found in the strategy to avoid the use of technology in the Anthropocene and to rely on the resilience or self-healing capacities of the natural environment or, if it is impossible, to improve technology and management of natural resources to take the human pressure off Earth's lifesupport systems. Although these two attitudes may represent two radically opposed worldviews and lead to radically opposed interventions to 'save' the Earth, they share one commonality however. Both unwittingly subscribe to the planetary management and control of planet Earth. Why? Also in the attitude towards the natural environment of planet Earth that is characterized by adaptation and responsiveness to planet Earth as an end in itself, the Earth is seen as a patient in need of help that we as humans have to manage and control in order to prevent her further degeneration. Instead of managing ourselves out of climate change by geoengineering, this attitude proposes to manage us back in the Holoscene. This shows that both attitudes rely on management and control, and that the only difference is found in its direction. At the same time, it is precisely this ambition of management and control that is no longer feasible in the Anthropocene as we have seen. Therefore, we argue for a new responsible professionalism in the Anthropocene in the next section.

\section{Towards a New Responsible Professionalism in the Anthropocene}

We argue for a new responsible professionalism in the food chain, because the complexity and wickedness of global problems like climate change can no longer be solved by the unilateral application of ethical norms in the Anthropocene. The wickedness of global problems like climate change means that professionals in the food chain have to deal with imperfect foresight. Our knowledge of the unintended or even irreversible and harmful consequences for future generations of new technologies related to $\mathrm{BBE}$ and PLF is principally imperfect and therefore insufficient to distinguish between good and bad strategies in the food chain. The unilateral application of ethical norms is further complicated because multiple actors have differing and often conflicting norms and value frames.

We argue for a new responsible professionalism in the food chain, because the Anthropocene shows the centrality of the normative dimension of the Anthropocene at the same time, and the economic, social and environmental challenges and opportunities it provides for responsible professionalism. Only by integrating this normative dimension in current practices, we are able to take full advantage of the shift in the food chain from a primary focus on market value to a focus on earth-oriented value in the Anthropocene. The new responsible professional has to deal with a double bind, namely the requirement of norms and values while experiencing that such univocal norms and values are not available at the same time.

We argue for a new responsible professionalism in the food chain, because the Anthropocene requires a new type of professional, who is able to take responsible action within the context of imperfect foresight. In the literature on education for sustainable development and sustainable entrepreneurship, the combination of normative competence and action competence is identified as distinguishing factor of sustainability oriented professionals, managers and entrepreneurs (Blok et al. 2016; 
Ploum et al. 2017). We can argue that the new responsible professionalism consists in the normative competence as ability to apply, negotiate and reconcile norms and principles in the food chain, which is unique in every situation because of the differences between the norms and interests of multiple stakeholders involved. The socio-ethical issues have to be weighed and revised over and over again because of changing circumstances or new insights, and the role of the professional involved in the food chain is to decide which norm to work with in a given situation. Next to normative competence, this requires action competence as the ability, based on critical thinking, reflection and incomplete knowledge, to actively involve oneself in responsible actions to improve the solution of the social-ethical issues involved in the food chain in general, and in BBE and PLF in particular. The combination of normative competence and action competence can be combined in a virtuous competence (Blok et al. 2016; cf. Ploum et al. 2017) that characterizes the new responsible professionalism in the food chain in the Anthropocene.

Contrary to the expert-engineer, who is the central figure in the technocratic approach, the new responsible professional doesn't consider partial technological fix solutions. He or she takes a food chain-perspective, is able to integrate the socioethical dimension in the further development of the BBE and PLF, doesn't only consult experts but all relevant stakeholders involved in the food chain, and takes the lead in the transition from a primary focus on market value to a focus on earth-oriented value in the food chain in the Anthropocene. Although much more research is needed to operationalise this new responsible professional, we propose the following competencies and abilities (cf. Blok 2018):

- To take a food chain perspective (systems thinking)

- To acknowledge the imperfect foresight of professionals in their dealings with wicked problems

- To apply, negotiate and reconcile norms and principles in the food chain (normative competence)

- The ability to reflect on (the limitations of) one's knowledge, intentions and behaviour.

- To take responsibility as actor involved in the food chain, based on the capability to reflect and engage in critical thinking (action competence)

- To enhance collaborative action with multiple market and non-market oriented stakeholders.

- to take risk by exploring and exploiting radical uncertain opportunities in the food chain. The risks and uncertainties involved do not only concern the economic risk, but also the social-ethical risks associated with the food chain.

- To engage in satisficing solutions that are satisfactory and sufficient to maintain the life support systems of planet earth in the Anthropocene, and are always open for future subversions, revisions and improvements at the same time. 


\section{Conclusion}

In this article, we have seen that the Anthropocene concerns a new geological epoch that necessitates u to take responsibility for Earth's life support systems. At the same time, the Anthropocene shows why the technocratic approach of management and control in the agri-food chain is less suitable and calls for a new responsible professionalism in the food chain. Because current conceptualizations of responsible professionalism unwittingly subscribe to this technocratic approach of management and control as well, we propose to conceptualize the new responsible professionalism based on two related moral competencies, and provided several key characteristics of the new responsible professional. In future research, these competencies and key characteristics have to be explored and substantiated in the practice.

Acknowledgements This article is an extended version of a keynote speech on new responsible professionalism during the Eursafe conference 2018 in Vienna (Austria). The building blocks of this article are heavily dependent on previous work that I was engaged in over the years together with many colleagues in Wageningen, and my team of students, PhD's, Post-docs in particular, that enabled me to develop this vision on a new responsible professionalism in the food chain in the Anthropocene.

Open Access This article is distributed under the terms of the Creative Commons Attribution 4.0 International License (http://creativecommons.org/licenses/by/4.0/), which permits unrestricted use, distribution, and reproduction in any medium, provided you give appropriate credit to the original author(s) and the source, provide a link to the Creative Commons license, and indicate if changes were made.

\section{References}

Baskin, J. (2015). Paradigm dressed as epoch: The ideology of the anthropocene. Environmental Values, 24, 9-29.

Blok, V. (2017). Earthing technology: Towards an eco-centric concept of biomimetic technologies in the Anthropocene. Techne: Research in Philosophy and Technology, 21(2-3), 127-149. https://doi. org/10.5840/techne201752363.

Blok, V. (2018). Information asymmetries and the paradox of sustainable business models: Toward an integrated theory of sustainable entrepreneurship. In: S. O. Idowu, et al. (Eds.), Sustainable business models: Principles, promise, and practice (pp. 203-225). Dordrecht: Springer.

Blok, V., \& Gremmen, B. (2018). Agricultural technologies as living machines: Toward a biomimetic conceptualization of technology. Ethics, Policy and Environment, 21(2), 246-263.

Blok, V., Gremmen, B., \& Wesselink, R. (2016). Dealing with the wicked problem of sustainable development. The role of individual virtuous competence. Business \& Professional Ethics Journal, 34(3), 297-327. https://doi.org/10.5840/bpej201621737.

Bos, J., \& Gremmen, B., (2013). Does PLF turn animals into objects? In Precision livestock farming 2013. Leuven: EC-PLF.

Bos, J., \& Munnichs, G. (2016). Digitalisering van Dieren. Verkenning precision livestock farming. Den Haag: Rathenau.

Bovenkerk, B., \& Keulartz, J. (Eds.). (2016). Animal ethics in the age of humans. Dordrecht: Springer.

European Commission. (2012). Innovating for sustainable growth-A bioeconomy for Europe. http:// ec.europa.eu/research/bioeconomy/pdf/bioeconomycommunicationstrategy_b5_brochure_web.pdf. Accessed 10 Oct 2018.

Farigone, J., Hill, J., Tilman, D., Polasky, S., \& Hawthorne, P. (2008). Land clearing and the biofuel carbon debt. Science, 319, 1235-1238.

Harfeld, J. (2010). Husbandry to industry: Animal agriculture, ethics and public policy. Between the Species, 10, 132-162.

Kolbert, E. (2011). Enter the anthropocene-Age of man. National Geographic, 219, 60-85. 
Morosov, E. (2013). So save everything. Click here. The folloy of technological solutionism. London: Penquin.

Murray, A., Skene, K., \& Haynes, K. (2017). The circular economy: An interdisciplinary exploration of the concept and application in a global context. Journal of Business Ethics, 140, 369-380.

Peterson, C. (2009). Transformational supply chains and the 'wicked problems' of sustainability: Aligning knowledge, innovation, entrepreneurship, and leadership. Journal of Chain and Network Science, 9(2), 71-82.

Ploum, L., Blok, V., Lans, T., \& Omta, O. (2017). Toward a validated competence framework for sustainable entrepreneurship. Organization \& Environment. https://doi.org/10.1177/1086026617697039.

Schlaile, M., Urmetzer, S., Blok, V., Andersen, A. D., Timmermans, J., Mueller, M., et al. (2017). Innovation systems for transformations towards sustainability? Taking the normative dimension seriously. Sustainability. https://doi.org/10.3390/su9122253.

Steffen, W., Crutzen, P. J., \& McNeill, J. R. (2007). The Anthropocene: Are humans now overwhelming the great forces of nature? Ambio, 36(8), 614-621.

Wathes, C. M. (2009). Precision livestock farming for animal health, welfare and production. Sustainable Animal Production: The Challenges and potential Developments for Professional Farming, 411-419.

World Commission on Environment and Development. (1987). Our common future. Oxford: Oxford University Press.

Zwier, J., Blok, V., Lemmens, P., \& Geerts, R. J. (2015). The ideal of a zero-waste humanity: Philosophical reflections on the demand for a bio-based economy. Journal of Agricultural and Environmental Ethics, 28(2), 353-374. https://doi.org/10.1007/s10806-015-9538-y. 